\title{
El paseo como método filosófico
}

\author{
Diego Clares \\ Universidad de Murcia \\ diego.clares1@um.es
}

Fecha de recepción: 21-4-2019

Fecha de aceptación: 5-8-2019

\section{Resumen}

Este artículo presenta la relación entre la filosofía y la actividad de pasear, recogida ya por algunos autores antiguos y revivida con más fuerza en nuestra época. Se examina cómo varios filósofos han descrito esta relación e intentado transmitirla mediante diversas concepciones de la misma, desde quienes menos vinculan el paseo con la actividad reflexiva hasta los que lo hacen con mayor rigor y profundidad. Además, se analiza si estas concepciones pueden contribuir a la construcción de un método filosófico pedestre más específico, susceptible de ser aplicado con rigor. En segundo lugar, se exponen y se definen una serie de criterios sistemáticos, defendiendo una concepción integral del paseo como método filosófico, es decir, valorando todo lo que puede aportar a la filosofía. Finalmente, se concluye que tal método no puede pertenecer a una rama filosófica especializada, sino a toda investigación y formación filosófica.

Palabras clave: caminar; metodología; Schelle; Baudelaire; Thoreau; Kessler; Benjamin; Careri

Abstract. The walk as philosophical method

This article looks at the relationship between philosophy and walking, already the subject of various classical writers and now enjoying a strong revival in our own times. It looks at how various philosophers have described this relationship and tried to explain it in different ways, from those who least link walking with reflective activity to those who link them more rigorously and deeply. In addition, it looks at whether these views can contribute to the construction of a more specific pedestrian philosophical method, capable of being applied rigorously. Second, a series of systematic criteria are laid out and defined, arguing for a global understanding of walking as a philosophical method; that is, assessing everything that can contribute to philosophy. Last, it concludes that such a method cannot belong to a particular branch of philosophy, but to all philosophical research and teaching.

Keywords: walking; methodology; Schelle; Baudelaire; Thoreau; Kessler; Benjamin; Careri

\section{Sumario}

1. Introducción

2. Qué es el paseo

3. Concepciones del paseo como actividad filosófica
4. Un método filosófico pedestre

5. Conclusiones

Referencias bibliográficas 


\section{Introducción}

Pasear, caminar, o moverse a pie, es una actividad común en la vida humana; es una capacidad que adquirimos y aprendemos al igual que el lenguaje, el pensamiento y las habilidades sociales. Está en relación con el mundo que habitamos, cómo lo entendemos, cómo lo medimos, cuán cómodos nos sentimos en él. En la vida humana común el paseo tiene múltiples connotaciones y aplicaciones, le otorgamos muchos sentidos diversos a los términos con que se relaciona: hablamos de un 'camino' o de un 'sendero' para referirnos a una doctrina o a un conjunto de creencias que definen una forma de vivir o de actuar; hablamos de 'dar pasos' para referirnos a las etapas de un proceso o de un método; llamamos 'movimiento' a las ideologías y a las acciones sociales; de quien admite su culpa o actúa con valentía decimos que 'da un paso al frente'; de las prostitutas decimos que 'hacen la calle', tal vez de forma semejante a como se decía en Gran Bretaña que los amantes 'salían a pasear' (Solnit, 2000: 340). Estos y otros muchos sentidos forman parte de nuestro lenguaje cotidiano, que está impregnado del tópico del paseo. Rebecca Solnit ha dado buena cuenta de ello en Wanderlust, donde la autora recoge una amplia historia del paseo, diversas nociones sobre este y su lugar en la cultura humana:

Caminar en sí no ha cambiado el mundo, pero caminar juntos ha sido un rito, una herramienta y un reforzamiento de la sociedad civil [...], es difícil imaginar una sociedad civil viable sin la asociación libre y el conocimiento del terreno que implica el hecho de caminar. (Solnit, 2000: 12)

También Antonio Casado comentaba hace poco la íntima relación entre el paseo y la desobediencia, entendiendo aquel como un modo de travesar libremente el espacio, en relación con lo que pretende el arte urbano (Casado, 2016: 1). No obstante, las reflexiones rigurosas sobre esta actividad en el ámbito filosófico son más bien escasas, y casi no aparecen en el ámbito académico. Pese a ello, pasear se está convirtiendo en un tema à la mode, con cada vez más publicaciones durante las últimas décadas. Los motivos son muy variados, pero principalmente pueden agruparse en tres grandes cuestiones:

1. Sus beneficios para la salud corporal, física y mental, para los sistemas cardíaco, respiratorio y neuronal.

2. La relación, de herencia principalmente romántica, entre andar y pensar, abstraerse, relajarse y desvincularse del mundo.

3. La problematización respecto a la comodidad de los medios de transporte actuales y su conveniencia frente al paseo.

Sobre cada una de estas cuestiones diremos algo en este artículo, pero el principal problema a resolver será otro: siendo tan diversos los sentidos de pasear y sus connotaciones, y estando desde la antigüedad vinculada esta actividad al pensamiento filosófico, ¿es posible trazar un método pedestre para la filosofía? Y, en tal caso, ¿cuáles serán sus características? 
A través del análisis de diversas consideraciones sobre la relación entre el paseo y la filosofía, veremos, por un lado, los motivos por los que podemos responder positivamente a la primera pregunta, y también mostraremos las particularidades que debiera tener un paseo a fin de servir como método filosófico. Para ello, definiremos primero la idea de 'paseo' que vamos a utilizar y sus aspectos característicos; en segundo lugar, recorreremos las ideas al respecto de algunos autores (Aristóteles, Karl Gottlob Schelle, Robert Walser, Charles Baudelaire, Frédéric Gros, Mathieu Kessler, Henry Thoreau, Walter Benjamin y Francesco Careri) ${ }^{1}$, analizando su cercanía con la empresa que nos ocupa y su aportación a la misma; finalmente, expondremos nuestra propuesta para un método filosófico pedestre.

\section{Qué es el paseo}

Pasear es, en su sentido más amplio, la actividad de moverse autónomamente a pie, es decir, dando pasos por uno mismo. Habitualmente empleamos en castellano varios términos para referirnos a ello, como 'caminar' y 'andar'. El primero, 'caminar', parece estar especialmente relacionado con la idea de seguir una vía marcada, aunque, en su origen celta, se refería a dar pasos (Corominas y Pascual, 1980a: 787). En galés, 'cam' significa 'paso', y en consecuencia el camino es, por así decir, el terreno pisado u hollado por el que solemos transitar. El segundo, 'andar', proviene del latín 'ambulare', y en consecuencia se refiere a vagar o dar vueltas (Corominas y Pascual, 1980a: 256). Al igual que este, otros términos, como 'marchar' (que, en su origen francés, significa «dejar una huella» o una señal [Corominas y Pascual, 1980b: 846]), nombran la actividad de pasear desde diferentes dimensiones, pero no tan descriptiva y ampliamente como podemos entenderla con la idea de poner un pie tras otro. Esta amplitud resulta especialmente importante cuando nos percatamos de que aquello que entendemos por 'pasear' tiene múltiples sentidos y connotaciones, y tanta variedad que no puede considerarse solamente desde la perspectiva del camino o del vagabundeo.

No tiene las mismas implicaciones el paseo como actividad atlética que como transporte: con el primero se pretende tonificar el cuerpo y alcanzar su máximo esfuerzo, mientras que el segundo alcanza su perfección en el mínimo grado de agotamiento; el primero, además, suele ser circular y tiene su fin en el mismo ejercicio, mientras el segundo es lineal y solo un medio para llegar a un destino. También hay grandes diferencias entre el paseo deportivo, o como entretenimiento, y la exploración a pie que realiza un investigador: el primero es ocioso y relajado, intranscendente y de valor principalmente estético, mientras que el segundo requiere minuciosa atención (por ejemplo, la de un biólogo o la de un arqueólogo) y organizar toda la información obtenida; el prime-

1. La selección bibliográfica ha sido ardua. Hemos intentado ceñirnos a unos pocos autores más representativos, claros y rigurosos en el tema, que han profundizado mayormente en sus concepciones, dejando a un lado muchas páginas de ideas vagas, generales o divulgativas. 
ro se beneficia de ir por vías conocidas y frecuentadas, pero el segundo será más provechoso cuanto más terreno inexplorado encuentre. En estos cuatro casos decimos que se está paseando, pero se trata de actividades claramente diversas. Decimos, por lo tanto, que son paseos en cuanto que tienen en común un movimiento autónomo a pie. Tal es la relación que establecen estas actividades con el paseo en sentido filosófico y con el método pedestre que expondremos a continuación.

Podemos observar en estos casos que las diversas formas de pasear se diferencian en dos aspectos fundamentales: los fines a los que están dirigidas y las relaciones que el agente (el paseante) mantiene con su entorno. Estas dos cuestiones sirven para definir no solo para qué paseamos y por dónde, sino también para analizar multitud de condiciones: el tipo de rutas adecuadas, el grado de esfuerzo físico y de tiempo recomendables, la vestimenta y los utensilios necesarios, la compañía, etc. Tendemos en cuenta, en adelante, estos dos factores para estudiar qué tipo de paseo requiere la filosofía y cómo podemos responder a sus características para elaborar un método filosófico pedestre.

\section{Concepciones del paseo como actividad filosófica}

La filosofía parece haberse relacionado con el paseo casi desde sus orígenes. La escuela filosófica fundada por Aristóteles pronto se conoció como peripatética

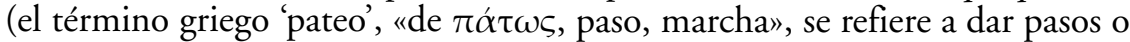
a «poner el pie» en un sitio [Sebastián, 1998: 1052]), según Diógenes Laercio (240: 229-230), debido a que dialogaba «en compañía de sus discípulos dando vueltas hacia la hora de las unciones de los atletas». Aunque el mismo autor señala, como otro posible origen, el que Aristóteles paseara con Alejandro, "que se recobraba dando paseos tras una enfermedad y charlaba con él» (Diógenes, 240: 230). La segunda explicación es menos creíble, ya que con el término se designa a toda la escuela y no solo al estagirita, pero aun así podría indicarse con ello que la actividad pedestre realizada en el Liceo no era inusual para Aristóteles.

Pese a esta antigua vinculación del paseo con la filosofía, esta no fue una cuestión por la que los filósofos helenos se preocuparan especialmente. Sí encontramos comentarios aislados, como la justificación del nombre de la escuela peripatética o la herencia del «Perípato» en el testamento de Teofrasto, en el que dice:

En cuanto al jardín y el paseo (Perípato) y todas las casas que dan al jardín, las lego a aquellos de los amigos nombrados luego que quieran permanecer siempre en la escuela y filosofar en común en este ámbito. (Diógenes, 240: 256)

Conocemos, además, la importancia del viaje para la cultura y la economía helénica. Que los filósofos antiguos, pese a la gran presencia del viaje y el paseo en el desarrollo de sus ideas, no pensaran en ello como parte de un método propiamente filosófico puede deberse a que se trataba de actividades cotidianas y no aquello distintivo de la filosofía: el razonamiento teórico. Como conse- 
cuencia, no encontramos tratados sobre el paseo en este sentido. Aunque no sabemos si en las obras que hemos perdido, muchos diálogos de Aristóteles y gran parte de lo escrito por Teofrasto, habría alguna referencia a los beneficios de la actividad pedestre para filosofar, que tanto parece valorar el filósofo de Ereso en su testamento. Tal vez el comentario de Aristóteles respecto a la finalidad del movimiento local, en el libro tercero de su tratado Acerca del alma

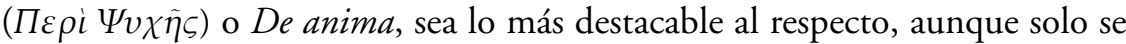
refiera con ello a que el fin de todo movimiento local es «el objeto deseable» (Aristóteles, 350 a. n. e.: 247), ya sea pasional o intelectual.

Pero no se otorgó una gran importancia al paseo como actividad metódica complementaria del pensamiento hasta casi el siglo XIX, pues, aunque podemos rastrear algunas notas tan marginales como las que hemos señalado en el mundo antiguo, hasta 1802 no se publicó la primera obra dedicada específicamente al paseo como actividad intelectual. Die Spaziergänge ${ }^{2}$, de Karl Gottlob Schelle, es la primera obra dedicada especialmente a desarrollar el paseo como una actividad de interés para el filósofo y para, en general, los intelectuales y los ociosos, por sus beneficios psíquicos ${ }^{3}$. No puede decirse lo mismo, no obstante, de las Ensoñaciones de un paseante solitario, de Jean-Jacques Rousseau (1782), puesto que en ella el filósofo solo hace recuento de sus ideas paseando, de algunas de sus andanzas, y unos muy breves comentarios sobre por qué decidió realizar tal actividad, pero ninguna meditación que profundice en sus características propias ni en la relación con la filosofía.

Pese a que Schelle, un auténtico desconocido para la historia de la filosofía, escribió este primer tratado sobre el paseo, no podemos asociar su obra con una concepción propiamente filosófica del mismo. Como bien indica Federico Silvestre en su introducción a la edición castellana del texto, esta actividad «debe relacionarse con la aparición de ciudades, burgueses, modernos jardines y nuevos ideales» (Schelle, 1802: 9). Este 'distanciamiento a pie' debía ser relajante y tranquilo, no agotar las facultades sino calmarlas. Schelle consideraba que el paseo «no debía ser ni demasiado largo ni demasiado empinado; ni demasiado solitario ni demasiado cansado», en una justa "mezcla de alegría y comodidad» (Schelle, 1802: 12). El paseo se presenta como una escapatoria al aburrimiento y a la melancolía, y no como un modo de reflexión al respecto. Esta actividad parece especialmente propia del dandi, tal como lo describió Baudelaire: «el hombre rico, ocioso, y que, incluso hastiado, no tiene otra ocupación más que ir en busca del placer» (1863: 91).

2. Mencionaremos la obra con este título, aunque se ha traducido al castellano como El arte de pasear. El motivo reside en que el término germano tiene importantes connotaciones por su etimología, híbrida de latina y anglosajona. El término 'spazieren', proviene del latín 'spatiārì', origen del castellano 'espacio' (Kluge, 1881: 683). Por lo tanto, podríamos entender este concepto con la idea de 'distanciarse a pie'. Como veremos, Schelle defiende en gran medida esta interpretación del paseo como un alejamiento respecto a las preocupaciones cotidianas.

3. Muy semejante en sus ideas fue su contemporáneo William Hazlitt, a quien excluimos de este artículo debido a que su obra sobre caminar es más breve y menos detallada que la de Schelle. 
Nuestro autor sajón define su paseo como una actividad que relaciona lo corporal y lo mental, pero en una forma muy específica: «el movimiento físico ha de constituir un alimento para la mente, para el cuerpo, un medio para estimular la salud, y cualquier actividad mental fatigosa desbarataría este doble efecto»; en consecuencia, los paseos que defiende en su obra «no tienen como finalidad la meditación» (Schelle, 1802: 34). Nos recuerda esta idea en múltiples ocasiones a lo largo del texto: «el interés que el paseante ha de tener por la naturaleza no ha de ser de orden intelectual» (Schelle, 1802: 38), «el tipo de ocupación mental al pasear ha de ser siempre leve y descansada para cumplir su propósito» (Schelle, 1802: 53). Entonces, jes este paseo algo específicamente corporal, y no una actividad mental? Schelle dirá justo lo contrario:

Evidentemente el movimiento del cuerpo no constituye ni con mucho el paseo $[\ldots]$ no es siquiera su auténtico componente. Lo que determina el verdadero paseo es de naturaleza intelectual [...]. Pero aunque el movimiento del cuerpo no constituya el paseo en sí, sí que es un condicionante necesario para que este tenga lugar, aunque solo sea de un modo pasivo, como cuando se pasea en coche. (Schelle, 1802: 117)

Siguiendo esta reflexión, con la que el autor descarta asociar dicha actividad necesariamente con el dar pasos o moverse uno mismo a pie, queda claro que la spaziergänge no es un paseo en el sentido que hemos expuesto al comienzo. Su propósito de estimulación mental resulta primario en su definición, hasta el punto de poder prescindir de aquello que definíamos basilarmente como acto de pasear. Su propósito es la relajación y la armonización entre la mente y las sensaciones corpóreas, por lo que Schelle se detiene a analizar la influencia de diversos entornos para la realización de tal actividad, y la conveniencia de ir a veces a pie y otras, para evitar el cansancio, en coche $e^{4} \mathrm{o}$ a caballo.

La actividad descrita en Die Spaziergänge no puede ayudarnos en el desarrollo de un método filosófico pedestre, debido, en primer lugar, a que no persigue, como su autor indica, una meditación o una reflexión intelectual, y por lo tanto no cabe filosofar durante su práctica; y, en segundo lugar, a que tampoco es rigurosamente un paseo, sino un movimiento que bien puede hacerse a pie o con otros medios. Podemos decir, no obstante, que constituye un método de relajación que puede realizar un filósofo, como cualquier otra persona, y que despeja la mente, pudiendo disponerla para realizar ejercicios intelectuales que, sin embargo, requieren otro método.

Más dispuesto a adoptar ese otro método se nos presenta Robert Walser, quien vincula su actividad intelectual y literaria con la de dar pasos. En El paseo (Der Spaziergang) el autor se describe a sí mismo como un individuo "que pasea tan a gusto como escribe; esto último en todo caso quizá un punto menos a gusto que lo primero" (Walser, 1917: 24). Walser define su actividad como un vagar sin rumbo fijo, o al menos sin intención de llegar pronto a su

4. Nos referimos, como puede suponerse, a los carros tirados por caballos y no a los actuales automóviles. 
destino; holgazanea, derrocha el tiempo y cruza por donde se le antoja, "pasando gallardo ante toda clase de gentes» (Walser, 1917: 30). Para el escritor suizo, la libertad del movimiento guiado por intereses ocasionales, por la curiosidad en unos u otros elementos del paisaje, es un elemento constitutivo de su actividad pedestre; pero también nos destaca cómo esto, a su vez, supone un beneficio para la imaginación literaria y la creatividad. Muestra de ello son los variados relatos entrecruzados en este ensayo, en los que Walser narra cómo importunó a un librero preguntándole si el libro más vendido era «realmente bueno» (1917: 14), o sus encuentros con jóvenes cantantes y con el espantoso gigante Tomzack.

Este desarrollo del paseo, aunque más literario que el de Schelle, nos aproxima a una idea más interesante para el método pedestre que perseguimos, ya que centra la atención en dos cuestiones íntimamente relacionadas con la filosofía: la libertad y la escritura.

Ahora bien, el modo en que Walser vincula la escritura con el paseo nos lleva a pensar también en otros modos de creación que pueden derivar de ello, ya que el concepto clave que los une es la imaginación, no solo la que nos relaciona con las palabras y las ideas escritas, sino también con la pintura o la escultura. En ello incidió más Baudelaire, en Le Peintre de la vie moderne, caracterizando al flâneur no solo como un caminante, sino también como un artista interesado en lo cotidiano, en todo cuanto sucede a su alrededor mientras pasea. Es un «observador, flâneur, filósofo, llámenlo como quieran», «es el pintor de la circunstancia y de todo aquello que esta sugiere de eterno» (Baudelaire, 1863: 57). Esta vinculación con la creación, tanto de obras artísticas como filosóficas, parece presentarse como una característica intrínseca de la actividad pedestre que necesitamos tener en consideración para valorar el modo en que pasear puede nutrirnos de ideas para la reflexión crítica.

Respecto a la libertad del paseo, se ha manifestado más recientemente Frédéric Gros en Marcher, une philosophie, traducido como Andar, una filosofía. El filósofo francés realiza una defensa similar a la de Schelle del paseo filosófico, contraponiéndolo a cualquier actividad atlética, pero prestando más atención al hecho de que su forma propia es el ir a pie, autónoma y libremente. Para Gros el ir a pie debería considerarse una actividad propia de la filosofía más que como un deporte o una actividad física, incluso antes que como un transporte (que, según el autor, puede realizarse con otros medios) (Gros, 2009: 9-10). El paseo que propone en esta obra, compuesta mayormente de comentarios a otros autores (Nietzsche, Rimbaud, Rousseau, Thoreau, Kant, etc.), es principalmente una actividad liberadora, relajada, lenta y abstraída. Pretende la desconexión con el mundo social, la búsqueda de alguna reconciliación con la propia naturaleza, con algún estado de vida salvaje, y el olvido de las obligaciones civiles y cualquier compromiso. Este objetivo pedestre llega incluso a deshacerse del diálogo y la interacción con cualquier acompañante, prefiriendo el silencio. Según Gros, «estar en compañía hace tropezar, obstruye, altera el paso», aunque «hasta tres o cuatro personas todavía se puede caminar sin hablar» (Gros, 2009: 63). Su característica más notable, no obstante, es la libertad. 
Gros distingue entre tres tipos de libertad que se alcanzan mediante el paseo: libertad suspensiva, libertad agresiva y renuncia. La libertad suspensiva consiste en «liberarse de la carga de las preocupaciones, olvidar por un rato los problemas» (Gros, 2009: 11). Es una suspensión de las obligaciones cotidianas, que permite dejarlas en casa y relajar el pensamiento; pero, además, tiene una importante consecuencia para la filosofía: «alcanza a liberarnos de las ilusiones de lo indispensable» (Gros, 2009: 11). Con esto quiere decir Gros que el paseo nos permite ver desde otra perspectiva lo que cotidianamente creemos necesario, reconsiderando si realmente lo es. Por su peculiaridad, el paseo es quizás la mejor actividad que permite variar nuestra perspectiva sobre el modo en que vivimos: no solo nos aproxima a otros lugares y nos hace conocerlos (lo que se puede obtener con un medio de transporte), sino que nos pone en contacto directo con ellos por nuestro propio pie, gracias a un esfuerzo personal que también nos exige mayor compromiso y preocupación (si vamos en coche, tan fácilmente como llegamos a un lugar nuevo podemos regresar; pero el paseo nos sitúa radicalmente en ese terreno, sin más escape que continuar andando, y nos pone en tesitura de vivir allí sin remedio, al menos durante el tiempo que dure nuestro paseo). Tal vez por ello Gros considera que únicamente el paseo nos otorga esta libertad.

«La segunda libertad es agresiva, más rebelde» (Gros, 2009: 13), se trata de una transgresión, de una ruptura radical con la vida cotidiana. Mientras que la primera libertad es más liviana, una sencilla posibilidad de reflexión y cambio, esta, dice Gros, es más radical y excesiva, y nos lleva al «límite de nosotros mismos y de lo humano» (Gros, 2009: 14).

Andar puede provocar esos excesos: un exceso de cansancio que lleva la mente al delirio, un exceso de belleza que sobrecoge el alma, un exceso de ebriedad en las cimas, en lo alto de los puertos de compaña (el cuerpo estalla). Caminar acaba por despertar en nosotros esa parte rebelde, arcaica: nuestros apetitos se vuelven toscos e intransigentes, nuestros ímpetus, inspiradores. (Gros, 2009: 14)

En cuanto a la tercera, es «la libertad del que renuncia» (Gros, 2009: 15). Una vez alcanzada la rebeldía y habiendo contactado con ese estado salvaje o arcaico, el tercer estadio consiste en abandonar por completo la vida civilizada, convertirse en un mendigo errante y vivir según uno mismo. Gros vincula esta libertad con los sabios orientales, que, habiendo obtenido una verdad universal, únicamente están, pero no actúan ni manifiestan voluntad alguna. «Es la máxima libertad: la del desapego total. Ya no estoy implicado, ni en mí mismo ni en el mundo. Indiferente al pasado y al futuro, no soy más que el eterno presente de la coincidencia» (Gros, 2009: 17).

La noción del paseo expuesta por Frédéric Gros en Andar es, en consecuencia, un movimiento hacia la negación de la sociedad y de la acción humana, tal como la ha considerado la tradición filosófica; un desplazamiento fuera de la civilización, que en un primero momento resulta útil para la crítica social y la reflexión ética y política, pero que conduce a un exceso rebelde y a un anihilamiento que renuncia a habitar racionalmente el mundo. Es difícil 
pensar que el fin de la filosofía sea compatible con tal abandono de la sociedad y de uno mismo, por lo que, pese a su aproximación al tema que nos ocupa y su sugerente concepción de la libertad suspensiva, esta propuesta no puede ser constitutiva de un método filosófico pedestre; queda siendo, antes bien, una doctrina fundada en el andar.

Consideremos por lo tanto que, para ser efectivo como método filosófico, el paseo debe cumplir esa primera libertad que define Gros. Ahora bien, el rechazo de la progresión que establece hasta la renuncia nos permite comprender una segunda característica fundamental: el compromiso con el mundo y la propia vida. Solo mediante tal compromiso es posible encauzar la libertad hacia la creación literaria que anteriormente indicábamos. En este sentido, podemos considerar la relevancia del concepto de viajero (Wanderer) de Mathieu Kessler (1999) en El paisaje y su sombra (Le paysage et son ombre). Este entra de lleno en la cuestión que nos interesa: cómo el paseo implica un compromiso para el filósofo y no es solo una actividad complementaria o una desvinculación. Kessler propone la actividad pedestre no como un medio para abstraerse, sino como una posibilidad de pensar situados en el mundo y relacionados directamente con él.

Para definir este tipo de relación, el autor lo distingue del turístico: «Un paseo apresurado, cuya finalidad sea la contemplación del "menor" punto de vista, del panorama más completo de la región, es la representación típica del turista» (Kessler, 1999: 36). La irremediable vinculación de toda observación con un punto de vista y la imposibilidad de obtenerlos todos con un único vistazo (aunque sea panorámico, pues el panorama también es una perspectiva), e incluso la grandiosa dificultad de aunar casi todas las perspectivas posibles, conducen a Kessler hacia una problematización de la conformidad turística y una defensa de la comprensión activa y atlética del entorno por parte del paseante.

Por un lado, el paisaje no tiene sentido con independencia del sujeto; por otro, conviene superar esta transcendencia subjetiva, si se quiere introducir una participación auténtica del sujeto en el «objeto», es decir, del hombre en el espacio geográfico [...]. La contemplación exige en este caso un atletismo del cuerpo y del alma. (Kessler, 1999: 40)

Kessler se refiere en este sentido al viajero, al Wanderer, «difícilmente traducible como "excursionista” " (Kessler, 1999: 23). Frente a la observación pura del paisaje, heredada de la estética kantiana, pone el acento sobre «algo casi olvidado: los paisajes se caminan, no solo se contemplan» (Torregroza, 2008: 87). Esto nos obliga a considerar los intereses y las condiciones vitales del viajero, de los que no puede desvincularse por completo durante el paseo.

En el extremo contrario al turista encontramos al comerciante y al conquistador, quienes tratan el entorno solo por intereses y no lo analizan ni lo valoran por sí mismo. De ahí que, distanciándose de la contemplación panorámica tanto como de la visión completamente impura de los fines políticos y comerciales, Kessler (1999: 23) afirma que «el viajero se caracteriza por el 
olvido del objetivo y por conceder al camino una atención mayor». En otras palabras: su fin no es otro que el conocimiento de su medio, un compromiso con el entorno por el que se desplaza. Esta cuestión resulta fundamental, porque si consideramos que el filósofo, cuando realiza un método pedestre, está filosofando, perder la atención sobre su entorno o no considerarlo entre sus objetos de conocimiento y reflexión implicaría el sacrificio de una de las dimensiones fundamentales que caracterizan al paseo: la posibilidad de relacionarnos con nuevos lugares, de obtener experiencias enriquecedoras y motivos de duda o deliberación.

El planteamiento de Kessler nos recuerda a la concepción del paseo limítrofe expuesta por Henry David Thoreau más de un siglo antes. En Pasear (Walking) realiza una defensa del cambio continuo de perspectiva mediante el paseo, que permite mantener lo que denomina una «vida fronteriza, en los confines del mundo en que solo hago ocasionales y pasajeras incursiones» (Thoreau, 1862: 242). La única forma de conocer realmente el mundo es visitándolo, desplazándose por él e interesándose directamente por sus características; todo otro conocimiento teórico es solo hipotético. De ahí que el filósofo norteamericano insista en la particular definición del «Saunterer», un individuo que vaga, bien buscando una Tierra Santa, bien sin hogar o sin tierra, según dos posibles orígenes de la palabra (Thoreau, 1862: 205-206). Este modo de atravesar el mundo, santerrar, le concede incluso al filósofo más teórico la oportunidad de contrastar su conocimiento con la realidad cruda, con una gran pluralidad de perspectivas, y acudir a "los Grandes Campos del pensamiento", donde podrá «ir a la hierba como el caballo y dejar todo arnés atrás en el establo» (Thoreau, 1862: 239). Tal paseante es un observador detallista y curioso, que transita contemplando todo su entorno. Es como un niño, ya que «el niño ve todo como novedad; está siempre ebrio» (Baudelaire, 1863: 62). El saunterer de Thoreau coincide de este modo con algunas características del flâneur de Baudelaire, que se encuentra "como en casa en todas partes» (Thoreau, 1862: 205; Baudelaire, 1863: 64).

Este paseo limítrofe, en consecuencia, requiere una libertad e independencia semejantes a la suspensión propuesta por Gros; pero no pretende con ello desvincularse del mundo ni de la sociedad, sino aportar una nueva visión al conocimiento humano y a la vida cotidiana, en el sentido propuesto por Baudelaire y Walser. El constante movimiento nos permite desarrollar tal perspectiva limítrofe o fronteriza, un pensamiento inquieto que no se conforma con su estadio y concepción actual y que comulga con el ánimo crítico que caracteriza a la filosofía. Este tipo de paseo, en el que uno es cómplice con el entorno, sitúa al caminante por los lugares, tanto naturales como civilizados, en una especie de anonimato social. Se permite "ver el mundo, ser el centro del mundo y mantenerse oculto al mundo» (Baudelaire, 1863: 64). Su actitud resulta espontánea y ajena a convenciones, caracterizada por el continuo interés y la independencia respecto a la ideología y la moral imperantes.

Frente a una sociedad sumergida en las tecnologías de la comunicación, que tiene acceso rápido a infinidad de información, el cometido de este paseo 
pudiera resultar poco alentador. Pero todo el conocimiento que estas nos proporcionan está mediado, es indirecto y está atravesado por intereses y concepciones determinadas. El interés del filósofo norteamericano por los parajes naturales y silvestres, por buscar la «materia cruda de la vida» (Thoreau, 1862: 226), tenía como objetivo la reconciliación de la filosofía con la existencia cotidiana, con las necesidades fundamentales de la vida y las cuestiones prácticas que las rodean, pero también la independencia respecto a la influencia creciente de los periódicos y la confianza ciega en la ciencia vigente, "pues ¿qué son las bibliotecas de ciencias sino archivadores de periódicos?» (Thoreau, 1862: 239). De modo semejante proponía, también, su proyecto en Walden, en cuyo comienzo expone:

Ser un filósofo no es meramente tener pensamientos sutiles, ni incluso fundar una escuela, sino tanto amar la sabiduría como vivir, de acuerdo a sus dictados, una vida de sencillez, independencia, magnanimidad y confianza. Es resolver los problemas de la vida, no solo teórica, sino prácticamente. (Thoreau, 1854: 16)

Este punto de partida, de carácter notablemente vitalista, vincula la filosofía con lo cotidiano, con lo que un caminante o un flâneur pueden hallar en la ciudad, o en un bosque cercano. El interés por los paseos, incluso los más silvestres, vuelve de este modo sobre la vida común y los intereses especialmente humanos y sociales del filósofo. Mientras andamos podemos rumiar nuestros pensamientos $\mathrm{y}$ «ser más susceptibles a algunas influencias importantes para nuestro crecimiento intelectual y moral» (Thoreau, 1862: 210).

El paseo thoreauviano requiere una mirada a lo actual, a lo cotidiano que sucede ahora a nuestro alrededor: «No podemos permitirnos no vivir en el presente» (Thoreau, 1862: 245). Ahora bien, esto no es lo único que obtenemos a través del paseo. Walter Benjamin destacaba que «en el callejeo irrumpen en el paisaje y en el instante tierras y épocas lejanas» (1982: 425). En el Libro de los pasajes (Das Passagen-Werk) hallamos algunas precisiones sobre el flâneur como un detective que no solo observa lo que sucede ahora, sino que es capaz de identificar la historia e imaginar el pasado. El paseo descrito en estos fragmentos por Benjamin es una investigación, una observación incisiva, incluso de cierto carácter científico. Es, igualmente, un momento propicio para el pensamiento crítico. El filósofo germano ilustra esta idea en relación con la observación de la economía paseando por los mercados, señalando que el flâneur se convierte así en «el explorador del capitalismo» (Benjamin, 1982: 431). El paseo se presenta como un método necesario para observar el mundo cotidiano filosóficamente, con independencia y curiosidad. Es valioso en la medida que nos aproxima al mundo y nos permite conocerlo por nosotros mismos, en primera persona y modulando nuestra experiencia según el movimiento, a un ritmo que nos es más natural y cuya armonía nos beneficia más; con el que podemos variar nuestro punto de vista y percatarnos de los límites de nuestro conocimiento actual.

Finalmente, Francesco Careri también ha prestado atención a la importancia de un método pedestre para el conocimiento y el juicio en el campo de la estética. Su mayor aportación a esta cuestión, en Pasear, detenerse (publicado 
originalmente en castellano), es la concreción de unas pautas generales para aplicar un método pedestre al estudio estético y artístico de la ciudad, que expone en forma de reglas destinadas a sus alumnos de arquitectura. Propone con ello el mejor intento de sistematización del paseo que hemos encontrado. Brevemente, podemos observar que su concepción de tal actividad es muy cercana a las de los autores mencionados, pero más precisa en los detalles:

— «Es preferible que solo vengan quienes no respetan el tabú de la propiedad privada», pues así "saltar las cercas se convierte de repente en la acción creativa más bella y regenerativa» (Careri, 2016: 116). Esta independencia respecto a las fronteras y los límites privados resulta fundamental para conocer en profundidad el entorno civil, aunque Careri no renuncia al respeto hacia los dueños de los terrenos y las viviendas.

— «Hay que aprender a encontrar al Otro» (Careri, 2016: 116). Es decir, no contentarse con observar desde lejos, sino aproximarse y hablar, intercambiar ideas, preguntar, y también hablar de uno mismo.

— «Nunca se debe dar marcha atrás. [...] Buscar una vía de salida es la mejor manera de explorar el territorio» (Careri, 2016: 117). "Pero aun si hubiera que hacerlo, no hay que desanimarse: el camino inverso muestra otro paisaje» (Careri, 2016: 126-127).

- «Quien pierde tiempo gana espacio». La exploración "está abierta a las desviaciones, a los cambios de rumbo, a detenerse a hablar con el dueño de la casa» (Careri, 2016: 117). Cuanto menos se restringe el tiempo del paseo y más nos permitimos perderlo vagando, más territorio recorremos y más conocimiento del lugar obtenemos.

— Es necesario tener "capacidad de penetración» (Careri, 2016: 117), es decir, habilidad para adentrarse sin problemas en cualquier lugar y adaptarse a sus condiciones. «Si conseguimos entrar y salir con fluidez, esto significa que el territorio es bastante permeable y permite un mayor número de encuentros y de conocimientos» (Careri, 2016: 117-118).

— «Hay que dormir al menos una noche fuera» (Careri, 2016: 118). Respecto a esto, señala el autor italiano que hace con sus alumnos paseos de dos días, que incluyen una noche fuera.

— «Tenemos que entrar en juego en tanto que artistas» (Careri, 2016: 118). Esto a veces es costoso, especialmente para quien no ha estudiado artes (ya que la mayoría de sus alumnos solo estudian arquitectura), y en consecuencia supone un reto. La propuesta de Careri consiste en lanzarse al vacío e improvisar, intentar transmitir algo aunque sea impulsivamente.

— «Hay que ir más allá de la representación» (Careri, 2016: 119). Por ello pide que sus alumnos «intervengan en la ciudad, que recuperen el placer de volver a apropiarse de los espacios, que descubran el derecho a transformar la ciudad con sus propias manos» (Careri, 2016: 120).

— «Hay que llevar a cabo performances relacionales» (Careri, 2016: 120). El fin de esta actividad es establecer una conexión con los habitantes del lugar, con ese Otro, que sea comprensible y participativa. 
- Finalmente, es una conclusión común de esta actividad negarse a hacer algún trabajo sobre los resultados de esta actividad como examen final. Para muchos alumnos, dice Careri, «la experiencia que hemos vivido ya es la obra que hemos realizado, y ninguna representación será capaz de hacerla revivir» (2016: 121).

Además de esta serie de pautas para sus estudiantes, el autor advierte otras consideraciones sobre este método: que se debe plantear como un proyecto indeterminado, "completamente contextual, relacional e imprevisible» (Careri, 2016: 126); andar «de forma estrábica, con un ojo puesto en la ruta y otro en todo aquello que está fuera de nuestro rumbo» (Careri, 2016: 127); y hacer una investigación de campo que esté "de parte de los "investigados" (Careri, 2016: 130), que sea valiosa para ellos más que para nuestro propio estudio.

\section{Un método filosófico pedestre}

Aunque Careri hace una excelente labor elaborando las pautas para su método pedestre, su concreción y aplicación especialmente estética nos obliga a intentar buscar un planteamiento más sistemático y adecuado, que sirva para toda la actividad filosófica. Retomando, igualmente, las diversas cuestiones que hemos analizado en el apartado anterior, nos ocuparemos ahora de hacer una sistematización clara y concisa para tal método.

La totalidad de autores que hemos considerado en nuestro análisis coinciden en una cuestión basilar: este paseo no puede realizarse si uno se encuentra aún vinculado y comprometido con las costumbres cotidianas o con programas ideológicos y morales, en la medida que estos determinen o condicionen en gran medida sus pensamientos. Si bien no hemos profundizado del mismo modo en todos sus comentarios al respecto, esta idea aparece continuamente en los discursos que hemos revisado. Tal vez la conceptualización de este requisito que más puede interesarnos es la que realizó Thoreau, al afirmar que «ninguna riqueza puede comprar la desocupación, la libertad y la independencia que constituyen el capital de esta profesión» (Thoreau, 1862: 207). En estas tres ideas se halla la libertad suspensiva que defiende Gros, así como el rechazo al tabú de la propiedad en Careri y otras nociones que ya hemos comentado y que nutren esta concepción, pero tal desglose permite analizar sus características con mayor profundidad.

Desocupación. Esta es la suspensión, por así decirlo, de las obligaciones cotidianas, de los compromisos sociales inmediatos, de las deudas y los trabajos pendientes. Tal falta de tareas también nos capacita para no temer al cansancio, a la distancia o a pasar la noche fuera. Regresando sobre una noción que hallamos en el mismo origen de la actividad filosófica, expuesta por Aris-

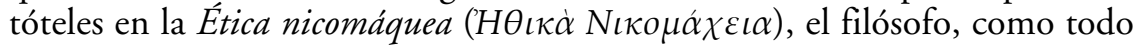
humano, "necesita de la salud corporal, del alimento y de los demás cuidados» (Aristóteles, 349 a. n. e.: 401). En consecuencia, al menos, el filósofo tiene que encontrar esas necesidades cubiertas o no requerir mucho esfuerzo para 
cubrirlas a fin de poder realizar su tarea, y también mediante el método pedestre debe tener esto en cuenta. Aunque, siendo más astutos, podemos percatarnos fácilmente de que, mediante el paseo, también podrá satisfacer algunos de estos requisitos, como encontrar alimento en el campo o en un mercado, y mejorar igualmente su salud corporal mediante el ejercicio, por lo que su desocupación respecto a las tareas cotidianas será más sencilla.

Libertad. Más allá de la idea de liberarse respecto a lo anterior, aquí queremos hacer hincapié en la necesidad de que la actividad filosófica sea una elección propia, voluntaria y meditada. En un interesante paralelismo, también el paseo debe tener este carácter: las rutas no pueden estar marcadas de antemano ni la dirección ser dogmática, ni estar ceñido a unos tiempos estrictos. El paseo debe realizarse, como señala Benjamin, sin meta ni objetivo fijo (1982: 422). Todo ello debe desaparecer para que uno pasee con el mismo ánimo que piensa, sin condicionantes que impidan desarrollar su actividad según su propio criterio. Por supuesto, no se podrán evitar algunos de estos condicionantes, pero deberán ser accidentales y nunca establecidos previamente por el hábito o el pensamiento (serán, por el contrario, los propios de la capacidad física, sensible e intelectiva de cada uno, de su situación geográfica, del clima, de la compañía, etc.). Finalmente, el criterio más importante será la volición y el deseo.

Independencia. Como ya hemos señalado, no verse constreñido por programas ideológicos, por convicciones morales o por requisitos legales es una condición indispensable para pasear con tranquilidad, pero también para filosofar. La suspensión de las afiliaciones políticas e intelectuales evita comprometer el rigor de nuestras meditaciones. De nuevo hay aquí una analogía entre andar y pensar: hacerlo por cauces marcados, atendiendo a señales y a doctrinas, implica la ausencia de crítica a la hora de juzgar si el destino y la conclusión de nuestra actividad se debe a un mérito propio o a la aceptación de un criterio externo. En este aspecto, el método pedestre conecta la filosofía con la investigación científica, como anteriormente hemos mencionado, en el sentido que tenía hasta que las ramas científicas se separaron académicamente del estudio filosófico. Es fundamentalmente empírico, permite contrastar informaciones directas en el mundo y examinarlas, y requiere el mismo cuidado para ello que cualquier estudio científico, pues debe cerciorarse de que no interpreta la experiencia obtenida de manera parcial. En consecuencia, la independencia es también una exigencia de pluralidad en los puntos de vista y una problematización de la perspectiva actual, pues hay condicionantes que no podemos negar, pero sí somos capaces de desplazarnos por ellos, buscar otros y contrastarlos para extraer conclusiones más adecuadas.

Estos tres requisitos nos proporcionan una base sobre la que realizar el método filosófico pedestre, pero están lejos de proporcionar una definición completa de tal actividad. Para definir las características específicas de esta, podemos considerar tres cuestiones: penetración, inquietud y deliberación.

Penetración. Mantenemos el término empleado por Careri por su especial concisión: es necesario que la actividad filosófica y pedestre se adentre en lo circundante con sencillez y facilidad, sin cambiar el orden cotidiano del lugar 
ni alterarlo sustancialmente, sin que su presencia sea violenta. Consiguiendo esto nos hallaremos en disposición de conocer el entorno como extranjeros, pero también desde el punto de vista de quien lo integra, conectando fluidamente las perspectivas ETIC/EMIC. Conviene pensar, en este sentido, el método pedestre como una investigación de campo, una indagación filosófica en el lugar, pero no limitada a una rama específica, sino abierta a todo aquello que podamos hallar. Para realizarlo necesitamos ejercitar tanto el cuerpo como nuestras habilidades sensibles y sociales, ya que no sabemos previamente cuán costoso será llegar al lugar, adaptarse a sus circunstancias, relacionarse con sus habitantes, etc., y es indispensable tanto tener un ánimo bien dispuesto y moldeable como una gran habilidad de percepción y comprensión de situaciones. De tal modo, nos adentraremos con más detalle en cada cuestión que investiguemos. El compromiso que conseguimos al ir a pie y depender de nuestras propias capacidades, intentando emplear los mínimos medios de transporte y comunicación posibles, situándonos sencillamente en el lugar y relacionándonos directa y vitalmente con él, refuerza esta capacidad de penetración, que también es en muchas ocasiones un requisito para movernos.

Inquietud. No solamente poder entrar y conocer en detalle cada elemento es importante, sino también plantear dudas y no conformarse con aquello que sepamos en un primer vistazo. Debemos interesarnos por el lugar, tener curiosidad y ambición por conocerlo en profundidad, no conformarnos con la simple observación ni con satisfacer un fin meramente teórico: hay que observar y contrastar a cada paso, hacer preguntas, dudar de las respuestas y no dar por sentada su interpretación, tomar notas de todo lo que pueda llamar nuestra atención, y procurar resaltar y destacar incluso lo más común, lo que habitualmente quedaría omitido. La labor filosófica consiste fundamentalmente en hacer preguntas respecto a lo que en general creemos conocer por ser habitual o tener respuestas tradicionalmente aceptadas; sobre todo ello cabe que indaguemos durante nuestro paseo. De tal modo, podemos viajar de un lugar a otro, visitar ciudades e investigar sobre su historia, su cultura, sus costumbres y tradiciones, las creencias de sus habitantes, su lenguaje, y la influencia de cualquier factor que caracterice y diferencie su circunstancia de la que encontramos en otros lugares. La inquietud debe animarnos a no parar de investigar y de plantear preguntas, adentrarnos en los motivos más sombríos, en las ideologías ocultas, en la simbología y en cómo cada uno de estos elementos es diferente o similar a otros allá donde vamos.

Deliberación. La acción más propia de la filosofía es la reflexión o deliberación sobre los asuntos que nos circundan, y, en este caso, sobre lo que hallemos durante nuestro paseo. Pero, como ya hemos indicado, más que pensar aisladamente sobre asuntos ajenos, nuestra tarea consistirá en pensar sobre la realidad que nos circunda, lo que deben permitirnos la desocupación, la libertad y la independencia, y que concretamos con las dos características que acabamos de definir: penetración e inquietud. La deliberación, finalmente, es la más clara de todas estas características. Además de adentrarnos en un lugar desconocido e indagar, la labor de un filósofo pedestre consiste en reflexionar 
sobre lo que ha hallado; más que acumular una serie de conocimientos adquiridos, de prácticas, costumbres y creencias, de detalles poco sabidos, y su análisis pormenorizado, este método debe concluir con un proceso de síntesis que, a partir del conocimiento obtenido, establezca una aportación original a la teoría, o una identificación de crisis y problemas con vistas a la reflexión práctica. Aunque puede que nuestra investigación solo encuentre una confirmación parcial de otra teoría, o una posible vía de revisión, incluso tal conclusión es valiosa para la filosofía. En cualquier caso, la deliberación parece ser en este método híbrida, en el siguiente sentido: tanto se realiza durante el paseo o el viaje, en los lugares transitados y en el trayecto de unos a otros, como tras el regreso, cuando revisamos nuestras anotaciones e intentamos reorganizar las ideas que surgieron. En consecuencia, el método pedestre incluye un momento sedente posterior: el de posarse para ordenar sus resultados, para dotarles de significado dentro de una rama de la filosofía, de cara a una conferencia o a una publicación.

Cabe señalar aún dos cuestiones más, relativas al fin del método pedestre:

1. No puede ignorarse el aspecto físico o corporal del paseo aunque lo tratemos como método filosófico. La filosofía es un saber sobre toda la vida, no solo sobre el intelecto y la actividad teórica, por ello no le es propio evitar lo corporal. Como ya hemos indicado, es una práctica que puede ayudarnos a obtener las necesidades más sustanciales, pero también está en conexión con todas las facultades vitales que distinguió Aristóteles en De anima: «nutritiva, sensitiva, desiderativa, motora y discursiva» (350 a. n. e.: 175). Mediante el paseo todas estas facultades pueden ejercitarse, por lo que el método pedestre resulta mucho más valioso aplicado por una filosofía vitalista que por otras más especulativas e interesadas principalmente en objetos de estudio abstractos.

2. Además, este método no pertenece ni tiene la pretensión de aplicarse con exclusividad a la ética, a la metafísica, a la estética, a la filosofía política, a la filosofía de la mente, del lenguaje o a cualquier otra rama especializada. Para cualquiera de estos objetos de estudio puede resultar beneficioso (aunque, dependiendo de su especialización, puede requerir otros métodos para realizar un estudio completo de su objeto), pero su fin en sentido estricto queda indeterminado, solo marcado por las pautas que ya hemos definido. También, en su aspecto más general, resulta un buen método para estudiantes y recién iniciados en la filosofía, tal como Careri lo aplica con sus alumnos.

Finalmente, podemos sintetizar todas estas cuestiones en la exposición de cinco etapas o momentos del método filosófico pedestre:

1. Salir, solos o acompañados, con desocupación, libertad e independencia, dirigiéndose hacia el lugar más atractivo, a donde creamos que encontraremos algo incógnito, aunque, por lo general, salimos a pasear desde casa, y en consecuencia ya conocemos la gran mayoría de lo que nos rodea 
inmediatamente, por lo que tenemos que andar bastante hasta hallar algo nuevo. Si salimos cuando ya estamos de viaje, habiendo pasado la noche fuera, este problema desaparece. También, para eludirlo de otro modo, es factible ir hasta algún lugar desconocido en transporte público (en relación con lo que comentábamos respecto a la penetración).

2. Contemplar el entorno penetrantemente y con inquietud. Pero no solo con la vista, sino con cualquiera de los sentidos, percibiendo el ambiente con toda nuestra capacidad y practicando para lograrlo con la mejor habilidad a fin de distinguir diversos matices.

3. Interactuar con aquello y con aquellos que nos encontremos, tanto con el medio inerte como con vegetales y animales, humanos o no, en la medida que nos sea posible. Tal interacción tiene dos momentos: primero, el propio de la penetración y la inquietud, que busca principalmente conocer al otro y hacerse uno mismo preguntas; segundo, el deliberativo, que puede realizarse en un contexto social preguntando a otros, discutiendo, etc. Con ello adquirimos un saber práctico y reflexivo.

4. Tomar notas, ya sea de forma esquemática, rápidamente mientras atendemos, observamos y escuchamos, o más detalladas, cuando con calma recapacitamos, recordamos lo sucedido, lo analizamos y lo sintetizamos en nuevas ideas, descripciones, comentarios, definiciones. El paseante, como señala Walser, está en una situación idónea para la creatividad y la escritura. En cualquier caso, estas notas deben tomarse cuando la percepción aún es reciente, para evitar su distorsión.

5. Revisar las ideas escritas y los recuerdos, regresar sobre nuestros pasos una vez hayamos vuelto y meditar sobre lo que hemos obtenido, contrastar los resultados de diferentes paseos, hablar con los compañeros y con quien no ha paseado a nuestro lado, escribir un artículo o una conferencia.

\section{Conclusiones}

Nuestras dos preguntas iniciales quedan solucionadas del siguiente modo: primero, hemos comprobado que hay tanto teorías como prácticas de métodos filosóficos basados en el paseo, y que tal aplicación (aunque tal vez se remonta a la escuela peripatética, de lo que no tenemos gran constancia) comienza a presentarse más rigurosamente a partir del siglo XIX, con las importantes definiciones realizadas por Henry Thoreau y Charles Baudelaire. Posteriormente, otros autores han hecho precisiones relacionadas con las suyas y han realizado grandes aportes a varias de sus cuestiones. Tal vez la más notable sea la sistematización de Francesco Careri. Hemos observado, por lo tanto, que sí es posible trazar un método filosófico pedestre. En segundo lugar, también hemos concretado las características que este debiera tener, atendiendo integralmente a las posibilidades que presenta la acción de pasear. Hemos definido el método filosófico pedestre en primer lugar como desocupado, libre e independiente, y también penetrante, inquieto y deliberante. Estas características permiten que sea un buen método para la filosofía más empírica y práctica, 
como la antropología y la ética, y también para la formación filosófica y la innovación en ámbitos no estrictamente especulativos. Como crítica, debemos considerar que solo mediante el paseo no nos adentramos en ramas filosóficas muy especializadas o que trabajen sobre objetos especialmente abstractos y especulativos, y en estos casos solo podrá ser un complemento ocasionalmente útil. También hemos distinguido cinco etapas del mismo, que constituyen a grandes rasgos el método pedestre:

1. Salir a pasear hacia lugares que desconocemos.

2. Contemplar el entorno penetrante e inquietamente.

3. Interactuar, primero para obtener más conocimiento, y segundo para implicarnos en discusiones y reflexiones.

4. Tomar notas.

5. Revisar nuestros resultados, contratarlos y exponer las conclusiones.

Señalábamos, además, que todo paseo se puede definir por sus fines y por la relación del agente con su entorno. Ahondando en estas dos cuestiones (a través de Baudelaire, Thoreau, Walser, Benjamin, Kessler y Careri) hemos alcanzado las siguientes conclusiones:

1. El fin del paseo como método filosófico es adquirir conocimiento preciso y crítico del mundo circundante, deliberar sobre él y alcanzar un pensamiento original o una revisión del mismo.

2. Quien lo realiza debe comprometerse con las condiciones de su entorno, depender en la menor medida posible de factores ajenos e interactuar sincera y abiertamente con cada elemento que halle para poder conocerlo con profundidad y rigor.

Finalmente, respecto a la relación de este método con las corrientes filosóficas, tal vez podamos señalar una mayor relación con la filosofía vitalista. Hemos indicado que el paseo puede ser un valioso complemento para la satisfacción de la totalidad de las facultades vitales o anímicas distinguidas por Aristóteles, por lo que una filosofía cuyo interés sea la vida y las cuestiones cotidianas o mundanas parece poder extraer un mayor beneficio a este método pedestre. El modo específico en que esto pueda lograrse, no obstante, pertenecerá a otra investigación.

\section{Referencias bibliográficas}

Aristóteles (349 a. n. e.). Ética nicomáquea: Ética eudemia. Madrid: Gredos, 1993.

- (350 a. n. e.). Acerca del alma. Madrid: Gredos, 1978.

Baudelaire, Charles (1863). «Le peintre de la vie moderne». En: Euvres complètes de Charles Baudelaire. III: L’art romantique. París: Michel Lévy frères, 1868. 
Benjamin, Walter (1982). El libro de los pasajes. Madrid: Akal, 2007.

Careri, Francesco (2016). Pasear, detenerse. Barcelona: Gustavo Gili.

Casado da Rocha, Antonio (2016). «La práctica caminante-desobediente como arte público independiente». Efímera Revista, 7 (8), 1-8.

Corominas, J. y Pascual, J.A. (1980a). Diccionario crítico etimológico castellano e hispánico. I. Madrid: Gredos.

- (1980b). Diccionario crítico etimológico castellano e hispánico. III. Madrid: Gredos.

Diógenes Laercio (240). Vidas y opiniones de los filósofos ilustres. Madrid: Alianza, 2007.

Gros, Frédéric (2009). Andar, una filosofía. Barcelona: Taurus, 2018.

Kessler, Mathieu (1999). El paisaje y su sombra. Barcelona: Idea Books, 2000.

KLUGE, Friedrich (1881). Etymologisches Wörterbuch der deutschen Sprache. Berlín: Walter de Gruyten, 1999.

Schelle, Karl Gottlob (1802). El arte de pasear. Edición de Federico L. Silvestre. Madrid: Díaz \& Pons, 2013.

Sebastián Yarza, Florencio I. (1998). Diccionario Griego Español. Vol. II. Barcelona: Sopena, 1999.

Solnit, Rebecca (2000). Wanderlust: Una historia del caminar. Madrid: Capitán Swing, 2015.

Thoreau, Henry David (1854). «Walden». En: The Writings of Henry David Thoreau. II. Boston: Houghton Mifflin \& Company, 1906.

- (1862). "Walking». En: The Writings of Henry David Thoreau. V: Excursions and Poems. Boston: Houghton Mifflin \& Company, 1906.

Torregroza Lara, Enver Joel (2008). «Del viajero al turista: Estética y política del paisaje urbano». Desafíos, 19, 71-103.

Walser, Robert (1917). El paseo. Madrid: Siruela, 2009.

Diego Clares es doctor en Filosofía por la Universidad de Murcia. Realizó su investigación sobre la ética del norteamericano Henry David Thoreau, del que ha traducido varios textos que se encuentran disponibles en su blog <https://thoreauencastellano.com>. Ha investigado la filosofía de Thoreau en relación con cuestiones medioambientales, sociales y políticas, y actualmente analiza su concepción de la filosofía y del intelecto. También investiga sobre filosofía de la religión y el pensamiento oriental. Ha publicado «Vida y wilderness: Actualidad de la ética medioambiental thoreauviana", Ágora: Papeles de Filosofí, 2018, 37(2).

$<$ https://orcid.org/0000-0002-3538-3107>

Diego Clares is a PhD graduate in Philosophy at the University of Murcia, Spain. His research was on the ethics of the North American writer Henry David Thoreau. He has translated several of Thoreau's essays, which are available on his blog (<https://thoreauencastellano.com $>$ ). He has researched Thoreau's philosophy on environmental, social and political issues, and is currently analysing his understanding of philosophy and intellect. He also carries out research on the philosophy of religion and oriental thought. He has published "Vida y wilderness: actualidad de la ética medioambiental thoreauviana”, Ágora: Papeles de Filosofía, 2018, 37(2).

$<$ https://orcid.org/0000-0002-3538-3107> 